tions of the value of screening tests may arise from failure to take the effects of these factors fully into account. Our values for the performance of the tests were obtained in a high prevalence group. This undoubtedly accounts for the high performance we have described for some of our tests.

It is presently considered that coeliac disease cannot be diagnosed on the basis of associated antibodies alone because of the occasional false positive or false negative results. ${ }^{3}$ Nevertheless, detection of such antibodies is of considerable value in screening for the condition,,$^{2.3}$ and, as we have shown, particularly in patients thought suitable for jejunal biopsy after appropriate clinical assessment and simple blood tests.

Testing for coeliac disease associated antibodies, particularly gliadin IgA by ELISA, promises to simplify and make more efficient the selection of patients for jejunal biopsy and perhaps in the not too distant future may allow the condition to be diagnosed with confidence without the need for biopsy. However, a similar high performance of this or some other assay would need to be shown in a less selected population before biopsy becomes unnecessary.

1 McNeish AS, Harms HK, Rey J Shmerling DH, Visakord JK, WakerSmith JA. The diagnosis of coeliac disease. A commentary on the curren practices of members of the European Society for Paediatric Gastroenterology and Nutrition (ESPGAN). Arch Dis Child 1979;54:783-6.

2 Guandalini S, Ventura A, Ansaldi N, Giunta AM, Greco L, Lazzari R, et al. Diagnosis of coeliac disease: time for change? Arch Dis Child 1989;64: $1320-5$

3 Walker-Smith JA, Guandalini S, Schmitz J, Shmerling Visakorpi JK. Revised criteria for diagnosis of coeliac disease. Arch Dis Child 1990;65:909-11.

4 Diagnosis of coeliac disease. Lancet 1991:337:590.

5 Dias J, Unsworth DJ, Walker-Smith JA. Antigliadin and antireticulin antibodies in screening for coeliac disease. Lancet 1987;ii: 157-8.

Hällström $\mathrm{O}$. Comparison of IgA-class reticulin and endomysial antibodies in coeliac disease and dermatitis herpetiformis. Gut 1989;30:1225-32.
7 Chorzelski TP, Beutner EH, Sulej J, Chorzewska H, Jablonska S, Kumar V, et al. IgA anti-endomysium antibody. A new immunological marker of dermatitis herpetiformis and coeliac disease. $B r \mathcal{Y}$ Dermatol 1984;111: $395-402$

8 Kárpáti S, Bürgin-Wolff A, Krieg T, Meurer $M$, Stolz W, Braun-Falco $O$. Binding to human jejunum of serum $\operatorname{IgA}$ antibody from children with coeliac disease. Lancet 1990;336:1335-8.

9 Elewaut A, Dacremont G, Robberecht E, Leroy J, De Baets MH. IgA isotyping of gliadin antibodies. A possible clue for a less invasive diagnosis of coeliac disease. Clin Chim Acta 1989;183:285-94.

10 Volta U, Molinaro N, Fratangelo D, Bianchi FB. IgA subclass antibodies to gliadin in serum and intestinal juice of patients with coeliac disease. Clin Exp Immunol 1990;80:192-5.

11 Unsworth DJ, Manuel PD, Walker-Smith JA, Campbell JA, Johnston GD, Holborow EJ. New immunofluorescent blood test for gluten sensitivity. Arch Dis Child 1981;56:864-8.

12 Gallen RS. Use of predictive value theory in clinical immunology. In: Rose NR, Friedman H, Fahey JL, eds. Manual of clinical laboratory immunology. 3rd ed. Washington: American Society for Microbiology, 1986:966-71.

13 Kumar V, Lerner A, Valeski JE, Beutner EH, Chorzelski TP, Rossi T. Endomysial antibodies in the diagnosis of celiac disease and the effect of gluten on antibody titers. Immunol Invest 1989;18:533-44.

14 Ascher H, Lanner A, Kristiansson B. A new laboratory kit for anti-gliadin IgA at diagnosis and follow-up of childhood celiac disease. $\mathcal{F}$ Pediatr Gastroenterol Nutr 1990;10:443-50.

15 Kelly J, O'Farrelly C, Rees JP, Feighery C, Weir DG. Humoral response to alpha gliadin as a serological screening test for coeliac disease. Arch Dis Child 1987;62:469-73.

16 Bürgin-Wolff A, Berger R, Gaze H, Huber H, Lentze MJ, Nussle D. IgG, IgA and IgE gliadin antibody determinations as a screening test for untreated coeliac disease in children, a multicentre study. Eur $\mathcal{f}$ Pediatr 1989;148:496-502.

17 Watson RGP, McMillan SA, Dolan C, O'Farrelly C, Cuthbert RJG, Haire M, et al. Gliadin antibody detection in gluten enteropathy. Ulster Med $\mathcal{f}$ 1986;55:160-4

18 Koletzko S, Bürgin-Wolff A, Koletzko B, Knapp M, Gruneklee D, Hertz G, et al. Prevalence of coeliac disease in diabetic children and adolescents. A multicentre study. Eur 7 Pediatr 1988;148:113-7.

19 Grodzinsky E, Hed J, Lieden G, Siorgren F, Strom M. Presence of IgA and IgG antigliadin antibodies in healthy adults as measured by micro-ELISA. IgG antigliadin antibodies in healthy adults as measured by micro-ELISA. Effect of various cutoff levels on specificity and sensitivity when
coeliac disease. Int Arch Allergy Appl Immunol 1990;92:119-23.

20 Scott H, Fausa O, Ek J, Valnes K, Blystad L, Brandtzaeg P. Measurements of serum IgA and $\operatorname{IgG}$ activities to dietary antigens. A prospective study of the diagnostic usefulness in adult coeliac disease. Scand $\mathcal{F}$ Gastroenterol 1990;25 $287-92$

(Accepted 30 August 1991)
Department of Clinical

Health, London WC1 1EH

Lyn S Chitty, MRCOG,

research fellow

\section{Luton and Dunstable} Hospital, Luton,

Bedfordshire

Gaye H Hunt, DMU, superintendent radiographer Jennifer Moore, DMU, senior radiographer

Michael O Lobb, FRCOG, consultant obstetrician

Correspondence to: Dr Lyn S Chitty, Paediatric Research Unit, Guy's Tower, London SE1 9RT

BMf 1991;303:1165-9

\title{
Effectiveness of routine ultrasonography in detecting fetal structural abnormalities in a low risk population
}

\author{
Lyn S Chitty, Gaye H Hunt, Jennifer Moore, Michael O Lobb
}

Abstract

Objective-To review the efficacy of routine prenatal ultrasonography for detecting fetal structural abnormalities.

Design-Retrospective study of the ultrasonographic findings and outcome of all pregnancies in women scanned in 1988-9.

Setting-Maternity ultrasonography department of a district general hospital.

Subjects -8785 fetuses.

Main outcome measures-Correlation of prenatal ultrasonographic findings with outcome in the neonate.

Results - 8733 babies were born during 1988-9, and 52 pregnancies were terminated after a fetal malformation was identified. $8432(95 \%)$ of the fetuses were examined by ultrasonography in the second trimester. 130 fetuses $(1.5 \%)$ were found to have an abnormality at birth or after termination of pregnancy, 125 of which had been examined in the second trimester. In 93 cases the abnormality was detected before 24 weeks (sensitivity $74.4 \%$, 95\% confidence interval to $66 \cdot 7 \%$ to $82 \cdot 1 \%$. Two false positive diagnoses occurred, in both cases the pregnancies were not terminated and apparently normal infants were born. This gives a specificity of $\mathbf{9 9 . 9 8 \%}(\mathbf{9 9 . 9} \%$ to $99.99 \%)$. The positive predictive value of ultrasonography in the second trimester was $97.9 \%(92.6 \%$ to $99.7 \%)$. Of the 125 abnormalities, 87 were lethal or severely disabling; 72 of the 87 were detected by the routine screening programme (sensitivity $82 \cdot 8 \%, 73 \cdot 2 \%$ to $90 \cdot 0 \%$ ).

Conclusion-Routine fetal examination by ultrasonography in a low risk population detects many fetal structural abnormalities but can present several dilemmas in counselling.

\section{Introduction}

Much evidence exists to suggest that routine ultrasonography in the second trimester improves the diagnosis of multiple pregnancies and the estimation of the expected date of delivery. But there are few reports of its use in screening for congenital malformations, such malformations occur in $2-3 \%$ of all infants and account for about a quarter of all perinatal deaths. ${ }^{12}$ Prenatal ultrasonography can detect many fetal malformations, ${ }^{3}$ about $90 \%$ of which occur in fetuses born to parents with no recognisable risk factors.

Persson and Kullander reported that in their routine screening programme 50 anomalies were detected but only 12 were detected early enough to allow termination of pregnancy. ${ }^{4}$ However, they do not state the number of abnormalities that were not diagnosed prenatally. Campbell and Smith reported detection of $85 \%$ of major anomalies and one false positive diagnosis of hydrocephalus in a routine screening programme, but the study was based in a unit with a particular interest

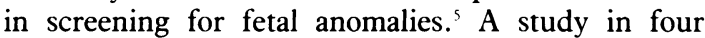
Belgian hospitals found that one third to one half of all 
fetal abnormalities can be detected by routine ultrasonography in a low risk population. ${ }^{6}$ These figures were supported by Rosendahl and Kivinen in their routine ultrasonography programme in which $39.4 \%$ of malformations were diagnosed before 24 weeks' gestation. ${ }^{7}$ Most recently the Helsinki ultrasound trial found that perinatal mortality was significantly lower in babies born to women who had routine ultrasonography and that $49 \cdot 2 \%$ of this reduction was due to the detection of major malformations; $40.9 \%$ of malformations were detected. ${ }^{8}$

We have reviewed the results of the screening programme at Luton and Dunstable District General Hospital to determine the effectiveness of ultrasonography in detecting fetal abnormalities in a low risk population in Britain.

\section{Subjects and methods}

About 4300 women are delivered at this hospital each year. All women who book early enough are offered ultrasonography at 18-20 weeks' gestation. All scans are performed by radiographers who have between one and 10 (average two) years' experience of obstetric ultrasonography. They are supervised by an obstetrician (MOL) and a radiologist, neither of whom have any particular skills in obstetric ultrasonography. About 15 minutes is allowed for each scan, which is designed to confirm viability, check the number of fetuses and the gestational age, determine the placental location, and examine the fetal anatomy. The box gives details of the anatomical checks that are made routinely. If, at the first examination, the fetus is found to be less than 18 weeks old or there is difficulty in completing the examination satisfactorily the woman is recalled for a second scan. When an abnormality is detected the findings are discussed with the obstetrician, who counsels the parents with our midwife counsellor. If necessary the mother is referred to a tertiary centre for confirmation of the anomaly and further investigations or management, or both. All parents are contacted the day after the initial discussion by the midwife to make sure that they have a good understanding of the consultation. This midwife is available for discussion at later stages in the pregnancy and after birth or, in the case of severe malformations, termination of pregnancy. Maternal serum $\alpha$ fetoprotein concentrations are not routinely measured.

Since the middle of 1987 we have kept a detailed record of all abnormalities detected by ultrasonography. We reviewed this record for 1988-9 and confirmed the pregnancy outcomes by reviewing the maternal and neonatal notes. When the pregnancy ended in fetal death the pathology reports were reviewed. The obstetric records are held on computer and include a record of all abnormalities found in neonates before discharge from hospital. We reviewed these records to determine infants with a congenital abnormality that was not detected prenatally. We have defined congenital abnormality as a structural abnormality which is present at birth and includes malformations, deformations, disruptions, or dysplasias. We excluded from the analysis abnormalities classified as of no serious medical consequence to the patient (uncomplicated spina bifida occulta; minor deformity of the nose, ears, and face; umbilical or inguinal hernia; undescended testes, hydrocele, phimosis, hypospadias; clicking hip, postural talipes; isolated skin lesions; functional cardiac murmurs; and single umbilical artery). ${ }^{9}{ }^{10}$ Most of these abnormalities cannot be detected by prenatal ultrasonography.

The sensitivity and specificity and predictive values of routine ultrasonography for detecting fetal structural abnormalities were calculated together with the $95 \%$ confidence intervals. ${ }^{11}$ Where the proportions

\section{Anatomical checks made during routine ultrasound examination}

Measurements:

Biparietal diameter

Head circumference

Femur length

Visualise:

Skull shape

Intracranial anatomy (ventricles, cerebellum)

Spine (longitudinal and transverse views)

Four chamber view of the heart

Thorax (lungs, heart:lung ratio, and positions)

Diaphragm

Stomach bubble

Anterior abdominal wall and cord insertion

Kidneys and bladder

All four limbs

Lips (1989 only)

approached $100 \%$ the exact method was used. As this study is retrospective we did not have accurate details of the number of scans each woman received. We therefore calculated the sensitivity, specificity, and predictive values in terms of fetuses examined rather than the absolute number of scans performed. For the purpose of the analysis we have also considered separately those abnormalities which are lethal or severely disabling (excluding unilateral cleft lip or palate, or both; talipes; unilateral limb anomalies; some renal anomalies; and familial skull anomalies).

\section{Results}

During 1988-9, 8733 infants were born and 52 pregnancies terminated after identification of a major malformation. Ninety five per cent of the mothers booked before 24 weeks. The perinatal mortality was $9 \cdot 3 / 1000$ births. Eleven (13\%) deaths were due to congenital malformations, of which seven were detected and two were not detected at the routine second trimester scan. In the two remaining cases severe malformations were identified by ultrasonography in the third trimester. Both of these mothers had booked too late to be offered ultrasonography in the second trimester. One other baby had died at the age of three months from congenital myotonic dystrophy. This baby was identified prenatally as having bilateral talipes. The mother knew that she had a "muscle problem" but this was not diagnosed as myotonic dystrophy until after she had delivered this affected child.

Of the fetuses examined by ultrasonography in the second trimester 125 had a structural abnormality; in 32 of these fetuses the abnormalities were not detected at this examination (tables I and II). In four cases the abnormalities were detected in the third trimester when the mother was scanned for another obstetric indication (table III). Five abnormalities occurred in infants born to mothers who had booked too late for or had failed to attend the routine fetal examination in the second trimester (table III). Four of these were detected

TABLE I-Summary of all fetal abnormalities found in study according to whether fetus examined by ultrasonography in second trimester

\begin{tabular}{|c|c|c|c|c|c|}
\hline & \multirow{2}{*}{$\begin{array}{l}\text { No of } \\
\text { fetuses }\end{array}$} & \multicolumn{2}{|c|}{ Abnormalities detected } & \multicolumn{2}{|c|}{ Abnormalities not detected } \\
\hline & & All & Lethal or severe & All & Lethal or severe \\
\hline $\begin{array}{l}\text { Examined } \\
\text { Not examined }\end{array}$ & $\begin{array}{r}8342 \\
443\end{array}$ & 93 & 72 & $\begin{array}{r}32 \\
5\end{array}$ & $\begin{array}{r}15 \\
4\end{array}$ \\
\hline Total & 8785 & 93 & 72 & 37 & 19 \\
\hline
\end{tabular}


in the third trimester. In 52 cases the pregnancy was terminated after a severe malformation was detected before viability, and in four cases the fetus died before 28 weeks' gestation.

Twenty one fetuses had karyotype determination ( 10 by fetal blood sampling and 11 by amniocentesis) after a structural abnormality had been identified. One abnormal karyotype was identified, triploidy in a fetus with a disorganised spine. One fetus was found to have hydrops and a cystic hygroma and died before a scheduled fetal blood sampling. Postmortem analysis of fetal skin showed that it had had Turner's syndrome. Of the 23 women who delivered an infant with an abnormal karyotype, 22 had had ultrasonography in the second trimester. Three of the affected fetuses had been found to have a structural abnormality (table IV). Two mothers had refused karyotype determination, and in the third case it was not offered because it

TABLE II - Structural abnormalities in fetuses examined by ultrasonography in second trimester

\begin{tabular}{|c|c|}
\hline Abnormalities diagnosed & Abnormalities not diagnosed \\
\hline $\begin{array}{l}\text { Central nervous system: } \\
1 \text { Dandy-Walker malformation }{ }^{\star} \\
2 \text { Holoprosencephaly`} \\
3 \text { Hydrocephaly }\end{array}$ & 1 Holoprosencephaly and micropthalmia \\
\hline $\begin{array}{l}\text { Neural tube defects: } \\
4 \text { Lumbar-sacral spina bifida } \\
1 \text { Cervical meningocoele } \\
6 \text { Anencephaly } \\
2 \text { Encephalocoele }(1 \dagger) \\
1 \text { Iniencephaly }\end{array}$ & \\
\hline $\begin{array}{l}\text { Face: } \\
1 \text { Bilateral cleft lip and palate } \\
1 \text { Unilateral cleft lip }\end{array}$ & $\begin{array}{l}2 \text { Cleft palate } \\
2 \text { Cleft lip }(1 \S) \\
2 \text { Cleft lip and palate } \\
1 \text { Cleft lip and polydactyly\|l }\end{array}$ \\
\hline 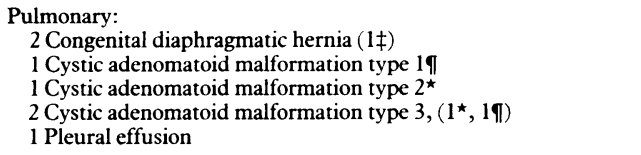 & 2 Pleural effusion \\
\hline $\begin{array}{l}\text { Cardiovascular: } \\
1 \text { Ventricular septal defect }(1 \dagger) \\
1 \text { Hypoplastic left heart } \\
1 \text { Atrial and ventricular septal defects }\left(1^{\star}||\right) \\
3 \text { Complex abnormality }\left(2^{\star}, 1 \dagger\right) \\
1 \text { Congenital heart block } \dagger\end{array}$ & $\begin{array}{l}2 \text { Hypoplastic left heart } \\
1 \text { Single atrium } \\
1 \text { Atrioventricular canal defect }\end{array}$ \\
\hline $\begin{array}{l}\text { Gastrointestinal tract: } \\
3 \text { Omphalocoele } \\
1 \text { Gastroschisis }\end{array}$ & $\begin{array}{l}2 \text { Tracheo-oesophageal fistula } \\
1 \text { Duodenal atresial }\end{array}$ \\
\hline $\begin{array}{l}\text { Renal: } \\
\text { 4 Renal agenesis } \\
1 \text { Bilateral dysplasia Type Ila } \dagger \\
1 \text { Bilateral dysplasia Type IIb } \dagger \\
1 \text { Bilateral hydronephrosis and hydroureter\| } \\
1 \text { Bilateral megauretert. } \\
5 \text { Unilateral moderate hydronephrosis }(1 \dagger) \\
3 \text { Unilateral multicystic kidney }(1 \dagger) \\
1 \text { Bilateral hydronephrosis } \\
1 \text { Bilateral enlarged extrarenal pelvis } \dagger \\
1 \text { Unilateral hydronephrosis plus contralateral multieystic kidney } \dagger \\
1 \text { Unilateral renal agenesis } \dagger \\
1 \text { Nephrocalcinosis } \dagger\end{array}$ & $\begin{array}{l}1 \text { Ectopia vesicae } \\
2 \text { Unilateral multicystic kidney } \\
1 \text { Bilateral renal dysplasia }\end{array}$ \\
\hline $\begin{array}{l}\text { Skeletal: } \\
1 \text { Unilateral tibial hypoplasia } \\
1 \text { Severe scoliosis } \\
2 \text { Disorganised spine }(1 \|) \\
3 \text { Unilateral talipes } \\
3 \text { Bilateral talipes } \\
1 \text { Abnormal skull } \\
1 \text { Absent hand }\end{array}$ & $\begin{array}{l}1 \text { Bilateral tibial and foot deformity } \S \\
1 \text { Missing digits on one hand } \S \\
1 \text { Complete syndactyly of one hand } \\
5 \text { Unilateral talipes }(1 \S) \\
1 \text { Bilateral talipes } \\
1 \text { Absent right hand } \S\end{array}$ \\
\hline $\begin{array}{l}\text { Recognisable syndromes: } \\
3 \text { Meckel-Gruber }\left(2^{\star}, 1 \dagger\right) \\
1 \text { Spondylocostal dysplasiał } \\
2 \text { Lethal multiple pterygium }(1 \dagger, 1 \ddagger) \\
1 \text { Cornelia de Lange's (with bilateral radial aplasia) } \dagger \\
1 \text { Congenital myotonic dystrophy (with bilateral talipes) } \dagger \\
1 \text { Noonan’s sydrome (with cystic hygroma plus short limbs) } \dagger \\
1 \text { Thanatophoric dysplasia } \dagger\end{array}$ & \\
\hline $\begin{array}{l}\text { Other: } \\
2 \text { Hydrops } \\
1 \text { Cystic hygroma } \\
1 \text { Unilateral hypoplasia of whole body } \\
6 \text { Multiple abnormalities }(1 \|)\end{array}$ & 1 Sacrococcygeal teratoma \\
\hline
\end{tabular}

$\star$ Diagnosed by tertiary centre.

†Diagnosed after delivery.

fOne fetus with affected sibling.

$\S$ Technical difficulties.

Associated trisomy.

ףLost to follow up; ultrasound diagnosis confirmed by tertiary centre only. was not appreciated that the abnormality might be associated with karyotypic abnormalities. In three infants the structural abnormalities had not been detected at routine ultrasonographic screening.

Fifty eight women were referred to a specialist centre for a second opinion or for fetal karyotype determination. The diagnosis was confirmed in 37 cases and modified in 15 cases. Six cases in which the fetus was found to be normal had all been referred for fetal echocardiography because of a suspicious four chamber view of the heart.

There was two false positive diagnoses. In both cases the mother had been referred for a second opinion, which had confirmed the findings. Neither pregnancy was interrupted. In one case there was persistent polyhydramnios. The stomach bubble was visualised but was always thought to be smaller than normal, possibly suggestive of a tracheo-oesophageal fistula. In the other case the fetus was found to have echogenic lungs, which can be associated with cystic adenomatoid malformation. The parents were counselled as to the possible serious associations with these findings but also of the possibility of a normal outcome of pregnancy. In both cases the pregnancy continued with regular follow up examinations at the referral centre to exclude any progression in the appearances. Both fetuses were normal at birth.

Table V summarises the statistical analyses. The sensitivity of routine ultrasonography for detecting congenital malformations in this population was $74.4 \%$ (95\% confidence interval $66 \cdot 7 \%$ to $82 \cdot 1 \%$ ) and the specificity was $99 \cdot 98 \%$ ( $99 \cdot 9 \%$ to $99 \cdot 99 \%)$. The positive predictive value for routine ultrasonography was $97.9 \%$ $(92.6 \%$ to $99.7 \%)$. If those pregnancies in which the fetus was not scanned in the second trimester were included then the sensitivity was $71 \cdot 5 \%(63.7 \%$ to $79 \cdot 3 \%)$. If only lethal or severely crippling abnormalities were considered then the sensitivity was $82 \cdot 8 \%(73 \cdot 2 \%$ to $90 \cdot 0 \%)$.

In addition to the abnormalities listed in the methods section several minor changes or markers were identified (these, when found in isolation, have not been included in the estimation of sensitivity or specificity). Nine fetuses had transient cysts of the choroid plexus, one of which also had talipes. Karyotype determination was done in the fetus with talipes and one other of the nine with this abnormality. Eleven fetuses with mild dilatation of the renal pelvis (pyelectasis) were identified. Two had karyotype determination. Nuchal oedema was found in three fetuses. In two it was associated with other abnormalities and in the third it resolved spontaneously. All three fetuses had karyotype determination. All infants in whom the choroid plexus cysts, pyelectasis, or nuchal oedema was an isolated finding were normal at birth. However, we do not have details of any neonatal renal scans in infants with prenatal mild pyelectasis.

\section{Discussion}

We have shown that routine ultrasonography by radiographers in a low risk population is effective in detecting many structural malformations. Direct comparison with other studies is difficult because they do not include details of the less severe abnormalities. However, our results (detecting $74.4 \%$ of all abnormalities in the screened population and $71.5 \%$ in the total population) compare favourably with other reports, in which the detection of major anomalies varies from $39 \cdot 4 \%$ to $83 \% .^{4.8}$ As shown in the Helsinki trial $^{8}$ the identification of some major abnormalities and subsequent termination of pregnancy probably affected perinatal mortality. In a recent report of perinatal deaths when ultrasonography was not done routinely $25 \%$ were due to lethal malformations. ${ }^{2}$ In 
TABLE III - Fetal abnormalities identified after second trimester

\begin{tabular}{|c|c|c|}
\hline Diagnosis & Indication for ultrasonography & Outcome \\
\hline \multicolumn{3}{|l|}{ By ultrasonography: in 3rd trimester: } \\
\hline Pleural effusions ( 2 fetuses) & Polyhydramnios & $\begin{array}{l}\text { Live birth, pleuroamniotic shunts } \\
\text { inserted prenatally }\end{array}$ \\
\hline $\begin{array}{l}\text { Bilateral renal dysplasia, } \\
\text { Potter IIb }\end{array}$ & Small for dates & Live birth awaiting transplant \\
\hline Unilateral multicystic kidney & Placental check & Live birth \\
\hline Hydrocephaly & Late booker & Live birth, shunt inserted postnatally \\
\hline Hypolastic left heart & Late booker & Neonatal death \\
\hline Complex heart lesion & Late booker & Neonatal death \\
\hline Obstructive uropathy & $\begin{array}{l}\text { Did not attend for second trimester } \\
\text { scan }\end{array}$ & Live birth, lost to follow up \\
\hline \multicolumn{3}{|l|}{ After birth: } \\
\hline Cleft lip and palate & Late booker & Live birth \\
\hline
\end{tabular}

TABLE IV - Details of structural abnormalities in neonates with an abnormal karyotype

\begin{tabular}{|c|c|c|}
\hline Karyotype & $\begin{array}{l}\text { Significant abnormality detected by } \\
\text { ultrasonography }\end{array}$ & Significant abnormality in neonate \\
\hline \multirow[t]{2}{*}{ Trisomy $21(n=15)$} & 13 None & $\begin{array}{l}11 \text { None } \\
1 \text { Duodenal atresia } \\
1 \text { Atrioventricular canal defect }\end{array}$ \\
\hline & $\begin{array}{l}1 \text { Hydronephrosis and hydroureter } \\
\text { I Not scanned }\end{array}$ & Confirmed \\
\hline Trisomy $13(n=2)$ & $\begin{array}{l}1 \text { None } \\
1 \text { Nuchal oedema and abnormal } \\
\text { heart }^{\star}\end{array}$ & $\begin{array}{l}\text { Cleft lip and polydactyly } \\
\text { Cleft lip and cardiac lesion }\end{array}$ \\
\hline Trisomy $18(n=1)$ & $\begin{array}{l}1 \text { Talipes and ventricular septal } \\
\text { defect }^{\star}\end{array}$ & Confirmed \\
\hline Others $(n=4)$ & 4 None & 4 None \\
\hline
\end{tabular}

$\star$ Fetal karyotype determination refused.

\section{Problems with routine ultrasonography for detecting fetal malformations in a low risk population}

\section{Problem}

Technical problem: maternal obesity

$$
\text { multiple pregnancy }
$$

fetal position

Uncertain outcome of recognisable lesion

Late presentation of some findings

Abnormality may not be detectable

Inadequate data on "minors changes"

Late booking for prenatal care

Example encountered
Unilateral talipes
Missing digits
Cleft lip
Absent hand
Tibial hypoplasia
Mild ventriculomegaly
Some renal lesions
Diaphragmatic hernia
Duodenal atresia
Pleural effusions
Some renal lesions
Sacrococcygeal teratoma
Tracheo-oesophageal fistula
Choroid plexus cysts
Mild hydronephrosis
Hydrocephaly
Cardiac abnormalities

our study only $13 \cdot 8 \%$ were due to this cause, and the potential for reducing perinatal mortality may be even greater as in six cases the parents elected not to intervene despite the identification of a potentially lethal fetal abnormality. Congenital abnormalities were detected in $1.5 \%$ of neonates before discharge from hospital. Ash et al found an incidence of 2-3\%, but their figure includes abnormalities such as pyloric stenosis and dislocated hips, which are often identified at a few weeks rather than a few days of age. ${ }^{1}$

Screening for fetal malformations in a low risk population is not without its problems, many of which we encountered (box). Routine screening with an option for intervention can be effective only if mothers attend early enough in pregnancy. In our population five abnormalities occurred in infants born to mothers who had not been screened in the second trimester. Technical problems accounted for five of the abnormalities that were missed in our study. In some cases though the underlying structural abnormality is present at the time of scanning, the sonographic signs develop later-for example, duodenal atresia. Other abnormalities, such as a tracheo-oesophageal fistula, may not be associated with signs detectable by ultrasonography. The prediction of outcome can be uncertain after some diagnoses. We encountered fetuses with diaphragmatic hernia and mild ventriculomegaly. In both cases counselling is difficult because there are no reliable prenatal prognostic features. ${ }^{12}{ }^{13}$ Both fetuses had a normal karyotype. The neonate with a diaphragmatic hernia died at birth from pulmonary hypoplasia. Serial scanning of the fetus with ventriculomegaly until 26 weeks' gestation showed no progression in the dilatation. The pregnancy ended in an intrauterine death at 34 weeks. Postmortem examination found gross hydrocephaly.

Probably the most common counselling problem in this population arose after detecting mild dilatation of the fetal renal pelvis or transient cysts of the choroid plexus. Both of these findings are known to be associated with karyotypic abnormalities, particularly if associated with other abnormalities. ${ }^{14}$ There are, however, very few data on the clinical significance of these variants in low risk populations, making counselling difficult, both with regard to fetal karyotype determinations and the possibility of adverse effects in childhood. We are currently participating in a large multicentre study which we hope will help to resolve this particular problem. ${ }^{15}$ Our current policy is to counsel parents that if these findings are isolated the chance of an associated karyotypic abnormality is small. Karyotype determination is available if the parents wish for it.

False positive diagnosis of a fetal malformation is a potential hazard, which could in extreme cases result in the loss of a normal infant. ${ }^{5}$ In our series there were two false positive diagnoses classified as having potentially serious implications. Both were confirmed at a tertiary referral centre, resulting in considerable and prolonged anxiety for the parents. Fortunately, neither pregnancy was interrupted. In neither case was definitive prenatal diagnosis possible. Increased echogenicity of the lungs can be a marker of cystic adenomatoid malformation, but this is usually associated with other findings in severe cases. In the fetus with bright lungs the parents were counselled optimistically because the changes were isolated and did not progress. Assessment of echogenicity can be difficult as it is subjective but in this case it was confirmed by an independent opinion. We encountered similar counselling problems in a fetus with normal sized, echogenic kidneys. Increased renal echogenicity may be a marker of renal dysplasia but in the presence of a normal liquor volume it is not possible to predict outcome with any certainty. ${ }^{16} \mathrm{~A}$ neonatal renal ultrasound scan in this case confirmed the prenatal findings but the renal function was normal. The importance of the changes remained

TABLE V-Sensitivity, specificity, and positive and negative predictive values (95\% confidence intervals) of routine ultrasonography

\begin{tabular}{|c|c|c|c|c|}
\hline & \multicolumn{2}{|c|}{ All abnormalities } & \multicolumn{2}{|c|}{ Lethal or severely disabling } \\
\hline & All fetuses & Fetuses screened & All fetuses & Fetuses screened \\
\hline Sensitivity (\%) & $71 \cdot 5(63 \cdot 7$ to $79 \cdot 3)$ & $74 \cdot 4(66 \cdot 7$ to $82 \cdot 1)$ & $79 \cdot 1 \quad(69 \cdot 3$ to $86 \cdot 9)$ & $82.8 \quad(73.2$ to $90 \cdot 0)$ \\
\hline Specificity $(\%)$ & $99.98(99.9$ to 99.99$)$ & $99.98(99.9$ to 99.99$)$ & $99.98(99.9$ to 99.99$)$ & $99.98(99.99$ to 99.99$)$ \\
\hline Positive predictive value (\%) ${ }^{\circ}$ & & $97.9(92.6$ to 99.7$)$ & & $97 \cdot 3(96 \cdot 0$ to $99 \cdot 7)$ \\
\hline Negative predictive value (\%) & & $99.6(99.5$ to $99 \cdot 7)$ & & $99.9(99.7$ to 99.9$)$ \\
\hline
\end{tabular}


uncertain until nephrocalcinosis was diagnosed by the regional nephrology unit.

\section{CONCLUSIONS}

Screening with ultrasonography in a low risk population can detect many fetal malformations and may reduce perinatal mortality. The demonstration of a normal fetus can be reassuring to the parents but, as we have discussed above, there are several limitations to such a screening programme, which is available only to women who book early enough. High levels of anxiety can be caused, not only with false positive diagnoses but also after identifying minor (possibly normal) variants. More data need to be collected in low risk populations concerning these normal variants together with the long term prognosis associated with many ultrasonographic findings so that we may counsel parents more accurately.

We thank Tricia Jones, midwife counsellor, for her help in collecting the data. LSC was funded by a Medical Research Council training fellowship.

1 Ash P, Vennart J, Carter CO. The incidence of hereditary disease in man. Lancet 1977; i:849-5

2 Chitty LS, Winter RM. Perinatal mortality in different ethnic groups. Arch Dis Child 1989;64:1036-41.
3 Nicolaides $\mathrm{KH}$, Campell S. Diagnosis and management of fetal malformations. Baillieres Clin Obstet Gynaecol 1987;1:591-622.

4 Persson PH, Kullander S. Longterm experience of general ultrasound screening in pregnancy. Am $\mathcal{F}$ Obstet Gynecol 1987;146:942-7.

5 Campbell S, Smith P. Routine screening for congenital abnormalities by ultrasound. In: Rodeck CR, Nicolaides KN, eds. Prenatal Diagnosis. Proceedings of the 11th study group of the Royal College of Obstetricians and Gynaecologists. London: RCOG, 1983:325-30.

6 Levi S, Crouzet P, Schaaps JP, Defoort P, Coulon P, Buelens P, et al. Ultrasound screening for fetal malformations. Lancet 1989;i:678.

7 Rosendahl K, Kivinen S. Antenatal detection of congenital malformations by routine ultrasonography. Obstet Gynecol 1989;73:947-51.

8 Saari-Kemppainen A, Karialainen O, Ylostalo P, Heinonen OP. Ultrasound screening and perinatal mortality: controlled trial of systematic one-stage screening in pregnancy Lancet 1990;336:387-91.

9 Jones LJ. Smith's recognisable patterns of human malformation. 4th ed. Philadelphia: W B Saunders, 1988:662-81.

10 De Wals P, Mastroiacovo P, Weatherall JAC, Lechat MF. Eurocat guide. Louvain: Catholic University, 1984:65.

11 Gardner MJ, Altman DG. Statistics with confidence. London: British Medical Journal, 1989:28-9.

12 Benacerraf BR. Fetal hydrocephalus: diagnosis and significance. Radiology 988;169:858-9.

13 Benacerraf BR, Adzick NS. Fetal diaphragmatic hernia: ultrasound diagnosis and clinical outcome in 19 cases. Am 7 Obstet Gynecol 1987;156:573-6.

14 Benacerraf BR. Prenatal sonography of autosomal trisomies. Ultrasound in Obstetrics and Gynaecology 1991;1:66-75.

15 Chitty LS, Chudleigh P, Pembrey ME, Campbell S. Multicentre study of antenatal calyceal dilatation detected by ultrasound. Lancet 1990;336:875.

16 Chitty LS, Griffin DR, Johnson P, Neales K. The differential diagnosis of enlarged hyperechogenic kidneys with normal or increased liquor volume: report of five cases and review of the literature. Ultrasound in Obstetrics and Gynecology 1991;1:115-21.
Respiratory Medicine Unit, City Hospital, Nottingham NG5 1PB

Rosalind Hill, MPHIL research assistant Jacqueline Williams, BA, clerical assistant John Britton, MD, lecturer Anne Tattersfield, MD, professor

Correspondence to: Ms Hill.

BMF 1991;303:1169-74

\title{
Can morbidity associated with untreated asthma in primary school children be reduced?: a controlled intervention study
}

\author{
Rosalind Hill, Jacqueline Williams, John Britton, Anne Tattersfield
}

Abstract

Objective-To determine whether an intervention programme based on existing school and community resources can reduce school absence and improve participation in games lessons and sport in children with unrecognised or undertreated asthma.

Design-Parallel group controlled intervention study.

Setting-102 primary schools in Nottingham: 49 were randomised to receive the intervention and 53 to be control schools.

Subjects-All children aged 5 to 10 years with parent reported absence from school because of wheezing in the previous year and taking no treatment or $\beta$ agonists only.

Interventions-Children with asthma were referred to their general practitioner for assessment of symptoms and treatment. Teachers were given education on asthma by the school nurse in 44 of the 49 intervention schools.

Main outcome measures-Changes in school absence and missed games and swimming lessons because of wheezing, and schools' policy towards management of asthma in school.

Results - Of 17432 children screened, 451 met the entry criteria -228 in intervention schools and 223 in control schools. $152(67 \%)$ children in intervention schools visited their general practitioner, of whom $39(26 \%)$ were given a new diagnosis of asthma and 58 $(38 \%)$ had treatment for asthma increased or changed. Over the next academic year mean (SE) parent reported school absence due to wheezing fell significantly, but to a similar extent, in both intervention and control schools $(0.82(0.11)$ and $1.09(0.21)$ weeks respectively). There was little change in school recorded absence or participation in games lessons and swimming lessons in either group. At the end of the study intervention schools were more likely to have improved aspects of management of asthma in school.

Conclusion-The intervention resulted in a majority of children being assessed by their general practitioner and improved teachers' understanding and management of asthma, but it did not result in any appreciable reduction in morbidity.

\section{Introduction}

Morbidity attributed to underdiagnosis and undertreatment of asthma in schoolchildren ${ }^{1.9}$ is common and should be preventable. During the early 1980s two uncontrolled studies in Newcastle found a considerable reduction in school absence because of wheezing after children with wheezing had been assessed and, if appropriate, treated for asthma. ${ }^{47}$ Since then the recognition of asthma and prescribing of drugs for asthma in children has increased greatly, ${ }^{10} 1^{\circ}$ but children continue to miss school because of apparently untreated or undertreated wheezing. ${ }^{10}$

To determine whether improvements can still be achieved in school attendance and participation in school activities of children with asthma and management of asthma in schools we conducted a randomised, controlled study of the effect of a simple intervention programme in 102 primary schools in Nottingham. The intervention was designed specifically to use health care resources already available to most schools so that if successful it would be suitable for more widespread implementation. The intervention entailed medical appraisal of children suspected of having undertreated asthma and, as children spend much of their time at school and staff may not be familiar with asthma and its treatment, ${ }^{12} 13$ it included a programme of education for teachers about asthma. 